\title{
MANDATO Y REVOLUCIÓN: \\ CABRERA INFANTE Y LA PÉRDIDA DE LA VOZ
}

\author{
POR \\ JuAn CRISTÓBAL CASTRO \\ Pontificia Universidad Javeriana, Bogotá
}

La voz significa esto: existe una persona viva, garganta, pecho, sentidos, que manda a través del aire esta voz, distinta de otras voces.

Italo Calvino

\section{I}

La voz en la cultura judeo-cristiana tiene connotaciones muy reveladoras para los creyentes, sobre todo cuando éstos necesitan de su autoridad. En el éxodo de la Biblia está muy claro el mandato que prodiga. Allí se le advierte a Moisés, luego de andar tres días cruzando el desierto sin agua: "Si de veras escuchas la voz de Yavé, tu Dios, y haces lo que es justo a sus ojos, dando oídos a sus mandatos, y practicando sus normas, no descargaré sobre ti ninguna plaga de las que he descargado sobre los egipcios; porque Yo soy Yavé, que te doy la salud" (Éxodo 15:26).

Escuchar es entonces no sólo venerar y respetar la ley, seguir los "dictados" del soberano padre de todas las criaturas del mundo, sino preservar la misma vida. La voz, por otro lado, es una y es clara: advierte, sentencia, promete y salva. No debe haber ruidos, ni intermediarios indeseados. Nada que perturbe la atención, y la voluntad del mandato. Su esencia es su misma presencia y pronunciación. No tiene más allá: es su acto de enunciación, sin elementos diferenciadores, interrupciones o digresiones. Es, en suma, puro acontecimiento y realidad; puro "performance" que, además, castiga o salva, dependiendo de cuán efectiva se le haya entendido y servido, y de cuán servil se le haya seguido y captado. El error puede ser mortal; también, la distracción, el descuido, la burla o la desviación. El precio puede ser el castigo y la expulsión de la "polis", del "pueblo", de la ciudad.

Este elemento, vital en las diferentes herencias de la cultura judeo-cristiana, se ha convertido en un dispositivo legitimador de muchas formas de poder en Occidente, bien sea institucional, religioso o personal. El presidente, el profesor, el padre, el líder, el magistrado, el presentador de radio o televisión, el cantante de rock, o el legislador, 
pueden en muchas ocasiones considerarse encarnaciones suyas. ${ }^{1}$ Las naciones y las revoluciones, en tiempos laicos, también tienen alguien que les dé voz: el sujeto que reifican como "pueblo", y el líder que lleva la batuta en el proceso de cambios. Sublevarse, con otros usos verbales, no es recomendable: puede ser claramente un gesto profanador, con lamentables resultados para algunos.

Comienzo con esta reflexión, porque en estas líneas ofreceré una lectura de la obra de Cabrera Infante a partir de su cuestionamiento de esa forma de la voz que encarna en la nacionalidad cubana. Su crítica propone un elemento contestatario e irreverente, que no se puede entender sin tomar en cuenta el contexto revolucionario y sus dispositivos de enunciación, que buscan por el contrario reificar una concepción de la "voz nacional" propia del "pueblo revolucionario". El epígrafe de Tres tristes tigres (1966) nos da algunos signos importantes: "El libro está en cubano. Es decir, escrito en los diferentes dialectos del español que se hablan en Cuba y la escritura no es más que un intento de atrapar la voz humana al vuelo" (11).

El "pecador" revolucionario nos dice algo peligroso: lo cubano está representado por diversos dialectos, y la escritura no es más que "un intento" por atrapar algo que vuela, algo que no está en ningún lugar seguro. No está en el cielo, no está en la tierra, y desaparece como un vacío que sólo deja la huella de una ausencia. El gesto implica muchas cosas. Una de ellas tiene que ver con una forma de concebir la literatura como un arte laico, polifacético y profanador. No es un simple medio evasivo de una burguesía industrial, que rinde culto a una subjetividad moderna y liberal. Tampoco es solo una rasgo de "clase", propio de una cultura elitesca o hegemónica. Es un espacio crítico, de cuestionamiento, que va más allá de la esfera racional, y se inscribe ciertamente en una tradición que se hace visible con Mallarmé, y sigue con Valery y las vanguardias.

Para entender, en todo caso, este gesto es importante reconstruir el escenario a partir del cual se labra y escenifica la rebelión literaria de la obra de Cabrera Infante, y que obviamente va más allá de la intencionalidad de la firma del autor, lo cual posee como colofón una lucha despiadada contra todo intento de homogeneización de la "voz cubana" que se dio en los aparatos propagandísticos de la revolución cubana en las décadas de los sesenta y setenta. Por eso, antes de entrar en materia con la obra del escritor, quisiera ver esto con más cuidado.

1 El problema de la "voz" y su metafísica ha sido desarrollado por Jacques Derrida, en un clásico texto sobre el tema: "La farmacia de Platón" (1969); aunque él hace hincapié en el platonismo, como momento inaugural. Después se han escrito numerosos análisis, algunos de los cuales mencionaré más adelante.

$111 \frac{\text { Revista Iberoamericana, Vol. LXXXII, Núms. 255-256, Abril-Septiembre 2016, } 551-569}{\text { ISSN 0034-9631 (Impreso) }}$ 
La historia empieza con un discurso, uno famoso que hoy en día sigue siendo motivo de discusión. En "Palabras a los intelectuales", Fidel Castro relata su encuentro con una mujer mayor de edad y ahí se pregunta: “¿Quién puede escribir mejor que ella lo que vivió el esclavo y quién puede escribir mejor que ustedes el presente?” (12). Casualmente, no hacía mucho se había prohibido la distribución de $P M$, y poco después se cerraría Lunes de Revolución. Como ha demostrado Juan Carlos Quintero Herencia en Fulguraciones del espacio: Letras e imaginario institucional de la Revolución Cubana (2002), ${ }^{2}$ esta intervención no puede verse sino vinculada con una obra importante de Miguel Barnet, Biografía de un cimarrón (1966), obra que abrió todo una abanico para repensar las funciones de este género y mostrar realidades que en otras formas no habían sido tomadas en cuenta. En ella, el autor nos relata la vida de Montejo, un esclavo que vivió casi todos los procesos de la Cuba pre-revolucionaria, y que terminó uniéndose a los procesos de cambio.

Hablar de novela testimonial hoy en día puede ser algo arriesgado, sobre todo cuando ha sido un género altamente debatido. ${ }^{3}$ Sin embargo, no hay que pasar por alto que en esta obra el autor se vale de distintas estrategias para homogeneizar una voz -la de Montejo-y hacerla transparente. Si bien es un intento válido de reconocer un diálogo con una "otredad", no deja de obedecer a ciertos mecanismos de ocultación y falseamiento que hay que explorar a fin de entender la manera como logra presentar una oralidad impoluta, prístina, clara. Hasta ahora ha sido poco estudiado el vínculo que hay entre nacionalismo y voz. ${ }^{4}$ Sin embargo, no es difícil comprobar que desde cierta instancia su representación se convierte en un dispositivo legitimador del "alma nacional". Para

2 Al hablar del discurso de Castro, Quintero Herencia dice lo siguiente: "Ese gesto de incorporación de la voz del 'otro' por y hacia el espacio de la letra (...) puede relacionarse con el gesto fundacional de la propuesta testimonial, según ha trabajado el cubano, Miguel Barnet, en Biografía de un Cimarrón" (371).

3 El tema es vasto. Apenas menciono las discusiones entre John Beverley y Roberto Morales, o entre Michael Zeuske y el mismo Barnet. A este respecto, ver los trabajos: Testimonio y literatura (1986), editado por René Jara y Hernán Vidal, los libros editados por Georg Gugelberger y Michael Kearney de ensayos en dos tomos de Latin American Perspectives con el título Voices of the Voiceless in Testimonial Literature (1991), y la edición especial La voz del otro: testimonio, subalternidad y verdad narrativa de la Revista de crítica literaria latinoamericana (1992), editada por John Beverley y Hugo Achugar. Sobre este género, profundamente saturado en las discusiones teóricas, recomiendo también las reflexiones de Beatriz Sarlo y David Stoll.

4 Destaco las críticas que se han hecho a la naturalización de la "lengua madre": el trabajo de Christopher Hutton sobre la oralidad "Language as Identity in Language Policy Discourse: Reflections on a Political Ideology" explica que "the notion that an individual's identity is derived primarily from their spoken or 'vernacular' language is one of the most radical in the history" (81), el mismo Kittler en su libro Discourse Networks 1800/1900 (1990) nos muestra cómo en el "sistema de inscripción" del siglo XVIII la lengua madre era producto de una naturalización de varias prácticas de lectura y escritura.

$111 \frac{\text { Revista Iberoamericana, Vol. LXXXII, Núms. 255-256, Abril-Septiembre 2016, } 551-569}{\text { ISSN 0034-9631 (Impreso) }}$ 
este acto de inclusión "mimética" es de gran importancia la escenificación, no sólo del sujeto autóctono como tal, sino también de su manera de hablar, de usar la palabra.

Bien sea para deificarlo, domesticarlo, o regularlo, la voz del autóctono, ese "Otro" que personifica la esencia identitaria, es siempre necesaria: su visibilidad marca un derecho de origen, imprescindible para todo movimiento con tintes nacionalistas. Para ello se requiere crear un efecto de correspondencia espacial y geográfica: quien habla debe usar marcas precisas que lo distingan y lo ubiquen en un espacio simbólico determinante. Gustavo Guerrero, interpretando a Detienne, en Historia de un encargo (2002) nos dice al respecto: “[...] la noción de autóctonia griega, que sirve de base a las nacionalidades modernas, supone que la voz del autoctonía nazca de la misma tierra desde donde éste habla e implica así una identidad simbólica entre el locutor y el lugar donde se realiza el acto de enunciación" (98).

Miguel Barnet aparece con su obra escrita en un momento importante de la revolución cubana, precisamente para ocupar ese lugar. Coincide con la centralización de la cultura; no en balde en 1970 la Casa de las Américas decide incorporar el género testimonial en su "Premio Anual" como una práctica literaria propia. De igual modo, por esas fechas se da la campaña de alfabetización -cuyo silabario Venceremos une varios métodos de enseñanzas, entre ellos el fonético, para darle "voz" al pueblo, que era analfabeta-, el auge de la poesía confesional, y la reificación de las confesiones de los líderes guerrilleros y personalidades públicas en eso que el crítico Roberto González Echevarría consideró como la "conversión del intelectual liberal a la ideología revolucionaria". 5

El testimonio y la confesión eran entonces figuras que buscaban legitimar la "voz" del nuevo sujeto revolucionario y se daban en contraposición a otras formas de representación. Era imprescindible entonces mitificar la "voz", utilizando diversos instrumentos intelectuales, culturales, ideológicos, sin prescindir por supuesto de la tecnología. ${ }^{6}$ De ahí que Fernández Retamar por esos tiempos, y recordando algunas de las labores de la importante revista Casa de las Américas, apuntaba en "Algunas nociones sobre la cultura en la Cuba revolucionaria" la necesidad de impulsar "los variados testimonios de la lucha militar, del trabajo diario o de la vida de hombres y mujeres del pueblo" (Quintero Herencia 45).

El núcleo seminal de este dispositivo es la encarnación del sujeto marginado, Esteban Montejo, dentro de la esfera letrada. Aunque su elección no fue azarosa; había un plan

\footnotetext{
5 "It can be safely said - dice González Echevarría, hablando del período revolucionario cubano- that conversión was a real phenomenon in Cuba" (“'Biografia de un Cimarrón' and the Novel of the Cuban Revolution" 251).

6 Fernández Retamar dice en un texto publicado en Casa de las Américas lo siguiente: "No es la literatura escrita, que requiere lectura, sino la literatura dicha la que va a desempeñar la unción primordial en esos años. Y dentro de la literatura oral, tendrá primacía el discurso, propagado de forma directa a través de la radio y la televisión" (cit. en Quintero Herencia 36).
}

$111 \frac{\text { Revista Iberoamericana, Vol. LXXXII, Núms. 255-256, Abril-Septiembre 2016, } 551-569}{\text { ISSN 0034-9631 (Impreso) }}$ 
muy claro. "Esteban -nos dice el autor en "La novela testimonio: socioliteratura"-, el Cimarrón, era un informante más entre otros ancianos, pero su vida era singular, completaba capítulos desconocidos, inéditos, de la historia de Cuba" (Barnet 21). La voz del "otro" revela una nueva historia, distinta a la oficial del momento, y el letrado sirve como medio - o acaso "médium"- de este acto.

Estamos entonces hablando de algo que va más allá de la simple recolección de información; detrás de la supuesta objetividad que el autor usa para legitimar su experiencia de encuentro, está el recuperar el vínculo con una memoria colectiva: "La novela-testimonio al rescatar ese orgullo popular, al reivindicar los valores que estaban escamoteados y revelar la verdadera identidad social del pueblo, ha contribuido al conocimiento y adaptación de la psiquis colectiva cubana a la idea de lo auténtico, de lo verdadero, de lo esencial" (Barnet, "Testimonio y comunicación” 52).

No se trata entonces de una simple tarea etnográfica. No se busca solamente investigar y comprender un "Otro", una alteridad recóndita, desconocida. Se trata, sobre todo, de una experiencia de encuentro trascendental con la figura del "pueblo cubano", 7 que descansa en una certeza: que esa voz se puede escuchar, que esa parte de la historia que representa se puede entender y transcribir claramente. Ese acto de inclusión pone en escena precisamente el deseo de toda causa revolucionaria: ser el medio por donde el excluido adquiere visibilidad y poder, y calza perfectamente con las intenciones del sector más dogmático del campo cultural cubano de ese momento de erradicar otras estéticas y propuestas culturales menos ortodoxas:

El pueblo de los cien años de lucha, que comenzó su pelea con un machete en la mano y continuó con un tanque, derribando las estructuras de una sociedad podrida, tenía unas historias diferentes, y lo que es más importante, una manera diferente también de contar esas historias, que sería expresada a través del testimonio. (Barnet, "Testimonio y comunicación" 47)

\footnotetext{
El "pueblo" es una figura retórica muy importante para la revolución. Se convierte en el contexto de la Cuba de los años sesenta, como ha dicho Duanel Díaz, en un "dispositivo totalitario" sobre el cual se pretende volcar todas las estructuras de poder a un mismo régimen de representación. Representarlo como marginado, inculto, pasivo ante manipulaciones foráneas, es muy importante porque justifica las empresas de cambio radical, así como la necesidad de domesticarlo para "su bien". Por otro lado, para estas fechas la visión anti-intelectual de la nación se supedita a la representación de ese sujeto. Díaz explica claramente esta política: "El dispositivo totalitario fue mordaza en los dos niveles de la esfera cultural: por un lado, reprimió a la alta cultura procedente de la tradición moderna, tachada de cosmopolita y antinacional; por el otro, al elemento popular, que en Cuba equivale en buena medida a lo afrocubano, como una barbarie que se resistía a los fines de la ilustración comunista, determinados por el doble objetivo de salir del subdesarrollo y prepararse para la defensa. Es justo en el año crucial de 1968, cuando el cierre por decreto de bares y cabarets acompaña a la movilización en las campañas agrícolas, que se intensifica la represión de los intelectuales negros que planteaban los problemas de la diferencia racial, y, más allá, de todos los que no se ajustaban al canon de Verde Olivo" (1).
}

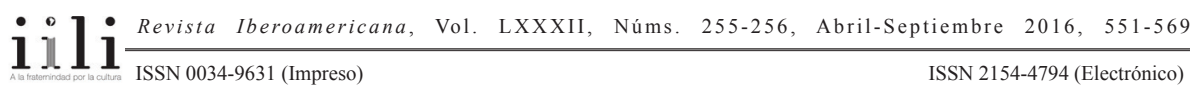


Este acto teatral descansa en una garantía teológica incuestionable: la voz del "otro" puede perfectamente revivirse, sin ruidos ni problemas, sin equívocos o vacilaciones; por eso, en otra ocasión Barnet dice que ha buscado "devolverle la voz a los desposeídos" (“Testimonio y comunicación” 59). Para lograrlo, el autor se vale de varias operaciones, que buscan reprimir cualquier otra versión que pudiera poner en cuestión la garantía hermenéutica del diálogo con Montejo. La primera es la de borrar el medio por excelencia donde se da el encuentro con Esteban: el grabador. Si bien confiesa que le ha servido no sólo para revelar el "ritmo y la secuencia" de la narración, sino también para mostrar el "tono del lenguaje y la anécdota", -incluso en otro momento confiesa que le ha servido para incluir algunos pasajes de "índole fantástico"-, no deja de verlo con reticencia. ${ }^{8}$ La razón es clara: “...esa falsa literatura simplista y chata, que es producto de la transcripción, no va a ninguna parte" ("La novela testimonio" 29).

La segunda operación busca atenuar la presencia del sujeto que escribe. Como se trata de una tarea cuyo principal protagonista es Montejo, Barnet debe ocupar un segundo puesto. Con el argumento de la "objetividad", que tanto proliferó en el periodismo moderno, Montejo intenta convencernos de que en el testimonio se debe buscar la "supresión del yo, del ego del escritor o del sociólogo" (23). No se puede mostrar ningún elemento de interferencia, ningún lugar de enunciación; no hay sino la pura escena de la narración del desposeído, que si bien presupone un diálogo previo, un encuentro, no deja de ocupar un lugar secundario dentro del mismo acto enunciativo. Aquí todo contexto queda en suspenso, todo elemento autobiográfico, e incluso, podríamos decir, ideológico. Pero no sólo se debe a una razón científica; también, se debe a una razón mayor, que tiene que ver con la verdadera misión del testimonio: despojarse de la individualidad del autor "para asumir la de su informante" que es, a fin de cuentas, "la de la colectividad que éste representa" (24).

La tercera operación tiene que ver con las marcas del estilo y la narración de Montejo, que va a ser corregida, procesada, digerida por Barnet. El mismo autor nos lo confiesa abiertamente al mostrarnos su poética verbal; si bien destaca que el testimonio debe reproducir la oralidad, advierte que ésta debe ser "decantada" ("Testimonio y comunicación" 51). La reproducción del lenguaje coloquial puede ser una "trampa" cuando se hace ilegible; sólo la garantía de legibilidad lo torna entendible, "universal", y aceptable, y para eso entra en escena el escritor "para elevar estas formas, estas estructuras, a otras formas, a otras estructuras: las cultas" ("La novela testimonio" 30). La conciencia popular no se muestra sino en ciertos gestos, que el letrado debe descubrir y alzar, debe reconocer y configurar. Él tiene la mirada privilegiada de lo que es importante y de lo que no lo es. "Hay que acabar de destacar ese criterio de que únicamente un lenguaje

Para él el "estilo y los matices" (52) serían de su propiedad - no la del sujeto colectivo que encarna Montejo, por cierto, sino de la persona individual que firma como Barnet-.

$111 \frac{\text { Revista Iberoamericana, Vol. LXXXII, Núms. 255-256, Abril-Septiembre 2016, } 551-569}{\text { ISSN 0034-9631 (Impreso) }}$ 
regionalista, un dialecto, puede dar garantía de autenticidad" (31), nos dice Barnet para posicionarse frente a cualquier tentativa populista. "Del lenguaje hablado, como del gesto social, hay que tomar su esencia", insiste (31).

Este tomar "su esencia" es, desde luego, producto de un trabajo delicado de reescritura, edición, cambio, que muestra que esta "otredad" sirve en tanto que representa un ideal. No interesa tanto su hablar peculiar. "Con el sudor de un lenguaje diáfano y revelador, asequible, con una concepción materialista de la historia, ubicados claramente en el centro de gravitación del hombre común, y contando con un instrumental específicamente aplicable, es posible contribuir a la ideologización y profundización de la identidad a través de géneros como la novela-testimonio", nos dice claramente el autor ("Testimonio y comunicación" 57). Barnet entonces, siguiendo el plan que Fidel esboza en su "Palabras a los Intelectuales", se borra como autor, borrando a su vez el medio que usa (el grabador), y así simula dejar hablar a quien no tuvo antes palabra.

Biografía de un cimarrón busca mostrar el periplo vivencial del personaje principal, desde sus primeros días como esclavo hasta su encuentro con la revolución. De cierta manera su periplo vital se convierte en un contra-discurso histórico, que subvierte y pone en contradicción la historia oficial cubana anterior a la revolución; por eso tampoco se le puede desvincular, como nos advierte González Echevarría, ${ }^{9}$ de los trabajos historiográficos de Moreno Fraginals, sobre todo de El Ingenio (1964), y de otros trabajos posteriores, como Los palenques de los negros cimarrones (1973) de José Luciano Franco, o Los guerrilleros negros (1975) de César Leante.

La voz aquí aparece representada bajo inscripciones bien precisas: arcaísmos, palabras provenientes de prácticas afrocubanas, giros dialectales, coloquialismos. No obstante, obedecen a una economía de la expresión que trata de atenuarlas y darle una solidez sintáctica y gramatical, que seguramente no tuvieron al momento de ser pronunciadas. Estas marcas, aunque tenues y corregidas, sirven como recursos retóricos para legitimar este acto de "posesión” espectral; simulan así la fusión con el estilo y la voz del pueblo cubano.

La otredad es así revivida, encarnada, en la seguridad hermenéutica del acto escrito, que pule y maquilla la oralidad analfabeta de Esteban con fines literarios e ideológicos. Dicho de otro modo: la letra es la voz; una voz corregida, articulada, maquillada. Después de este proyecto Barnet tratará, siguiendo la lógica teleológica del "Geist" revolucionario, de integrar otros modelos de voz en su obra posterior. ${ }^{10}$ Lo

9 Ver trabajo "Biografía de un cimarrón: And the Novel of the Cuban Revolution".

10 Ahora bien, si en Canción de Rachel (1969) muestra un cambio, no es tan radical como pareciera. Este testimonio, mucho más plural en cuanto a los materiales que usa y en cuanto a las voces que representa, nos describe la vida de Rachel, una actriz y cabaretera, hija de inmigrantes, que llega a ocupar un lugar importante dentro de la historia cultural y artística cubana. El autor busca varias estrategias para "relativizar su testimonio", destacando menos al personaje en sí que al tiempo que representa: "la era

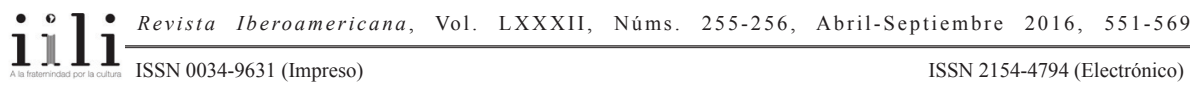


importante, en todo caso, es que para ese momento su obra está en consonancia con toda una política de la "oralidad" que pretende erigir una homología entre revolución, pueblo y voz con propósitos propagandísticos.

Con Guillermo Cabrera Infante vemos un distanciamiento frente a este "núcleo duro" de la nacionalidad, una separación que progresivamente se irá radicalizando, promoviendo un movimiento contrario al de Barnet: si éste acopla la voz para servir a la letra, el autor de Tres tristes tigres (1967) desfigura la letra para mostrar la imposibilidad de una voz. Ya desde sus primeros cuentos más militantes en Así en la paz como en la guerra (1960) vemos una puesta en crisis de una garantía teleológica del sentido, que muestra una conciencia temprana del grado de opacidad que gira en torno a todo acto de comunicación, y que bien nos evidencia su posición frente al pacto que procura reinstaurar el autor de Biografía de un cimarrón. En el cuento "Abril es el mes más cruel", una historia hermética y hasta minimalista donde se cuenta el suicidio de una mujer sin dejarnos entrever claramente sus motivos, el narrador nos sentencia claramente: "Las palabras siempre traicionan" (Así en la paz 71).

De igual modo, en estos primeros cuentos se ven formas plurales de explorar la verbalidad cubana. Por ejemplo, en "Rato de Tenmealla" la narradora nos habla violentando abiertamente la sintaxis y la ortografía. De igual modo, lo vemos en las voces que aparecen en los diálogos del cuento "Balada de Plomo y Yerro", donde destacan precisamente algunos giros que rompen con la norma escrita de manera jocosa y divertida, como cuando uno de los personajes dice "Cuidaonolalealguien", o como cuando otro pregunta, sorprendido:“¿Cuáldellos?” (24).

Sin embargo, en una viñeta que se inscribe dentro del texto en una especie de epílogo (como nota al margen de las viñetas de corte realista y revolucionario) vemos un elemento todavía más representativo. Allí se describe la presencia de unos letreros escritos en las paredes en un lugar desconocido y abandonado; escritos anónimos, en forma desordenada y algunos con errores tipográficos, hechos a rayas o pitas. Los mensajes son variados, pero la mayoría de ellos tratan de criticar el régimen dictatorial de Batista, desde sus respectivas voces, desde sus estilos y, sobre todo, desde sus "errores" ortográficos; llama la atención, a este respecto, que el autor cataloga estas

republicana", y contrastando su testimonio con otros personajes. Frente a la univocidad de la voz de Montejo, se contrapone la voz contrastada y relativizada de Rachel, quien si bien se ve con cierto decoro y dignidad, no se deja de tachar de manera muy sutil de mujer de la vida. Si el cuerpo del primero -un cuerpo masculino, guerrero, de color- representa el cuerpo restituido del alma nacional, el de Rachel -de una mujer, hija de extranjeros, fiestera- muestra el de la putrefacta republica que había entrado en decadencia.

$111 \frac{\text { Revista Iberoamericana, Vol. LXXXII, Núms. 255-256, Abril-Septiembre 2016, } 551-569}{\text { ISSN 0034-9631 (Impreso) }}$ 
inscripciones la "verdadera escritura revolucionaria" (205). Con semejante escena el autor pareciera decirnos que el "desposeído" no habla una lengua entendible, sólo nos muestra marcas, inscripciones, hechas en las pitas de las paredes; muchas de ellas en un lenguaje coloquial y cómico.

Sin embargo, visto en perspectiva, pareciera que en Cabrera Infante, pese a esa temprana conciencia de la fragilidad verbal, quisiera naturalizar el "choteo" como una forma de la cubanidad que se da precisamente en el desvío humorístico y en el error ortográfico. Por eso las pintas son la "verdadera literatura revolucionaria" y en la mayoría de los casos éstas son divertidas y jocosas. Con todo, a diferencia de Barnet, no busca tematizarlo como un dispositivo nacional. Además, también a diferencia del escritor testimonial, no interviene para circunscribir los límites de la interpretación de su obra, porque en ella y fuera de ella muchas veces hay un cuestionamiento de la autoridad del escritor.

Tiempo después, esta convicción que en sus inicios sólo aparece como sospecha, se hace más patente en su ruptura con la revolución en 1961, a raíz de la prohibición del documental de su hermano PM y del cierre de Lunes de Revolución. Ya en el lúdico prólogo de Un oficio del Siglo XX (1963), una recopilación de sus reseñas de cine escritas para la revista Carteles, muestra un claro escepticismo ante cualquier acto de enunciación, a través del juego meta-referencial, de la parodia verbal y de las falsas alusiones. Sin embargo, no es sino con Tres tristes tigres, obra cuyo destino va casi en paralelo con la de Barnet, donde se ve claramente un intento de poner en cuestión toda representación de una voz cubana, clara y aprehensible.

De este modo, y siguiendo la lógica que índica los indicios del epígrafe, no es difícil percatarse cómo en dicha novela se ven otras formas de neutralizar la garantía de una voz cubana, clara y entendible. La primera es la diseminación. Vemos precisamente muchos "testimonios": el de Estrella, el de la Cuba Venegas, el de Kodac, el de Seseribó, el de Silvestre, el de Bustrófedon, y muchos otros más, que hablan hasta no poder. Testimonios que no caen ni en la tentación victimaria, ni en el sentimentalismo heroico: son voces que se niegan y se contradicen, que guardan secretos y mienten. Voces de mujeres, niñas, hombres, señoras y hasta extranjeros que han estado en Cuba; voces de grupos marginales, de personas de clase media, de mulatos, blancos y negros. Voces que muestran varios dialectos y marcas, que a veces son groseras y otras irónicas o reticentes, dependiendo de quién sea el sujeto que las encarne.

La segunda forma para neutralizar esta garantía verbal está dada en la misma mediación. Todo testimonio está representado como trascripción de algún medio; el acto de enunciación no es unívoco o transparente, se da en un lugar preciso que se pierde en sus versiones y revisiones. Así vemos aparecer de una u otra forma a la radio, el cine o la televisión. Nadie está a salvo. Ni siquiera Bustrófedon, que no quería ser grabado, o la misma Estrella, que cantaba a "capella" y también se negaba a ser grabada. Para

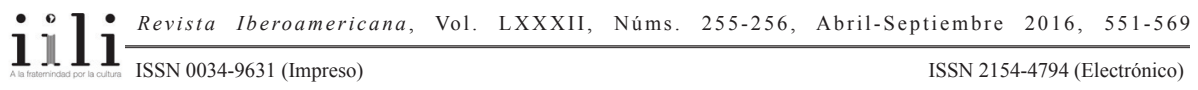


Valeria de los Ríos Tres tristes tigres es una novela "mediada y mediática, y su novedad no radica tanto en la captación minuciosa de un modo de hablar existente, sino más bien en la forma en que la escritura misma se revela como un medio que reproduce de manera simbólica a otros medios, específicamente el cine, el gramófono y la máquina de escribir" (1). Por su parte, Josefina Ludmer nos dice que la novela "invierte el valor del esquema platónico: no es 'el original' oral perdido lo sublime, sino el sistema de transcripciones" (504). Y es verdad: la continua transcripción, en la que se desvía el texto inicial al adjudicarle algún error, implica un diferimiento continuo de un espacio vacío que ya fue ocupado: “[...] el grafismo' resulta 'más alto' que el fonetismo porque está más alejado del original 'real'; la imagen reproducida vale más que el original y el 'traidor' se transforma en el verdadero héroe del texto", insiste la autora argentina (504).

El núcleo duro de la nacionalidad podría estar representado en la voz de Estrella, la mujer que canta a "capella" y por eso la única que puede mostrar una voz no mediada, o mejor dicho: sólo "mediada" por el aire. Su "melos" podría encarnar no sólo "la fuentes místicas del lenguaje" ("Meta-final" 229), como nos dice Roberto González Echevarría, sino también los orígenes terrenales de la nacionalidad -que Cabrera Infante cifra menos en la historia que en la geografía- $;{ }^{11}$ aunque, como toda fuente, es cambiante e inaccesible, de modo que su contacto se hace imposible y problemático. Ello se ve precisamente al ser uno de los pocos personajes que muere en la novela, que bien realza esta imposibilidad. Por eso sólo en una versión inédita -que pensó el autor en incorporar como final de la obra- es que aparece, y sólo como cadáver que ha fenecido en el exterior y que debe ser traído a Cuba. ${ }^{12}$

En definitiva, la voz de la Estrella, en contraste con la figura de Montejo de Barnet, es inasequible. Y frente a su "phoné" melodiosa, lugar de una posible esencialidad que no puede ser revivida o adquirida, aparece Bustrófedon, quien es pura inscripción, juego de palabra, trauma, y quien marca el símbolo de ruptura entre letra y sonido. Símbolo del cambio continuo, del error y la mala interpretación: este personaje representa ese lugar de la palabra siempre corrompido y desviado, siempre en continua mutación, es decir, el lugar de la inscripción.

11 William Luis, uno de los más importantes estudiosos de la obra de Cabrera Infante, coincide en esta visión. En “'Aire puro me gusta el aire puro': PM, Lunes de Revolución y la composición de Tres tristes tigres" ve la Estrella como "una figura poética de Cuba" (242), y aclara: "Ella es la oscura estrella brillante, un oxímoron natural, una estrella oscura que brilla a la vez, un tropo que encierra lo español y lo africano, lo blanco y lo negro, características de la cultura cubana" (242). Me parece que el mismo González Echevarría apunta a esto cuando afirma: "Porque es negra y cantante, Estrella puede verse en un plano alegórico como la encarnación de la cultura y el conocimiento de la tradición cubana" ( $L a$ voz de los maestros 230).

12 No hay que olvidar que el personaje La Estrella, fue la cantante Freddy Cuba que muere cuando Cabrera Infante vive el altercado de PM, experimentando así los primeros momentos de incomodidad con el régimen. De hecho, ello lo anima a ir pensando en Tres tristes tigres. De modo que el trasfondo de la novela es melancólico, y no necesariamente "celebratorio".

$111 \frac{\text { Revista Iberoamericana, Vol. LXXXII, Núms. 255-256, Abril-Septiembre 2016, } 551-569}{\text { ISSN 0034-9631 (Impreso) }}$ 
Entonces el periplo que abre Un oficio del siglo XX, sigue en Vista del Amanecer en el trópico y Tres tristes tigres, y termina con Exorcismo de Esti(l)o hace una exploración crítica de la cubanidad y de las formas de su voz, desmantelando todo intento esencialista por situar la identidad en una sola sonoridad. Se podría decir que parte de su búsqueda es un enfrentamiento no sólo con la univocidad de una oralidad cubana pura y accesible, sino también con una historia que se arma teleológicamente a partir de ese gesto originario de representación.

También es un momento, vale añadir, donde Cabrera Infante está reinventándose como autor, asumiendo su condición de exiliado, planteándose una nueva relación con su tradición nacional y con la tradición literaria occidental; no en balde las figuras de Joyce y Borges cobran un acento mayor, sustituyendo los resabios que quedaban en él de Hemingway o Sartre.

Su condición de exiliado, que se acentúa al mismo tiempo que Barnet se convierte en una intelectual orgánico del régimen, problematiza en cierta medida su necesidad de intervenir sobre el sentido de su obra. ${ }^{13}$ El contrapunto es claro: uno se vale de su autoridad revolucionaria para marcar y fijar la interpretación, mientras el otro, poniendo en cuestión su misma autoridad, termina siendo fiel al abanico de voces que se insertan en su escritura.

Lo importante, en todo caso, es mostrar que un rasgo que explica parte de su estilo se encuentra en la tensión que generaron las pugnas que hubo en el primer período de la revolución; pugnas no sólo de posiciones políticas, sino también estéticas. ${ }^{14}$ En el caso de Cabrera Infante esa pérdida de lugar dentro del proceso revolucionario lo lleva a escenificar una desgarradura que se mostrará en la necesidad de intensificar todavía más el cuestionamiento de la univocidad de la voz cubana. Después de todo, y a los

${ }_{13}$ Es verdad que su marginación no puede verse desde una pura victimización, pues se sabe que junto con Carlos Franqui tuvo un papel protagónico dentro de la revolución, y es cierto que a veces sus críticas parecieran provenir todavía desde cierta nostalgia por un poder que ya no tiene. También es verdad que, si bien al principio la revolución fue de talante más democrático, esto no quiere decir que no tuviera algunos gestos autoritarios y sectarios que Cabrera Infante no criticó abiertamente. Además, otras personas fueron las que vivieron en carne propia el carácter dictatorial del régimen cubano, como el mismo Reinaldo Arenas, por sólo mencionar el caso de un escritor reconocido. Sin embargo, todo ello no invalida su injusta marginación y el talante excluyente de la revolución. Por el contrario: en cierta medida, lo comprueba.

14 En muchos de los trabajos de William Luis bien se muestra la relación de Cabrera Infante con el grupo de Carlos Franqui, seguidores del Movimiento 26 de Julio, que giraban en torno al periódico Revolución, donde la página literaria Lunes de Revolución era dirigida por el autor de Tres tristes tigres. Este grupo se oponía a las concepciones estéticas e ideológicas del Partido Socialista Popular (PSP), -partido comunista de Cuba- y del ICAIC, Instituto e Industria Cinematográficos, presidida por Alfredo Guevara, que tendían a privilegiar una estética neorrealista, afín al realismo social y a la ideología comunista. Con la prohibición del documental $P M$, que al parecer surgía en contraposición al trabajo Cuba baila, los campos en pugna se distancian y Fidel Castro decide marginar al primero, privilegiando al segundo.

$111 \frac{\text { Revista Iberoamericana, Vol. LXXXII, Núms. 255-256, Abril-Septiembre 2016, }}{\text { ISSN 0034-9631 (Impreso) }}$ ISSN 2154-4794 (Electrónico) 
fines de este estudio, se trata de una exclusión que atañe menos a una persona -la firma Cabrera Infante-, que a una manera de entender y representar la voz (o voces) cubana(s).

No hay que olvidar que Cabrera Infante, junto con otros importantes escritores, representaba un espacio estético menos resistente a la modernidad, donde no se veía con tanto miedo la cultura de los medios de comunicación, y se aceptaba con menos trauma las innovaciones y conmociones que éstos creaban sobre la grafía y su dominio alfabético. Una vez que se impone la vía comunista más dogmática, la revolución apuesta por la estética del imaginario del realismo soviético, que, junto a cierta visión antropológica, pretendía rearmar el pacto mimético en un intento mesiánico de restituir la voz a la letra, tal como vemos con el género testimonial de Barnet, que pasó a convertirse en la obra por excelencia de la revolución.

\section{IV}

En definitiva, se trata entonces de dos visiones de la letra que están en pugna: representar la voz inarticulada, el ruido, que genera la voz mediada por medios y sujetos plurales, o representar la voz articulada del imaginario ortográfico y nacional. Una y otra en perpetuo conflicto hasta que la revolución -o más bien Castro- termina por decidirse por una.

Esta distinción tiene implicaciones teóricas que van más allá del contexto nacional cubano, y se remiten a dos formas de entender la escritura y la voz, que han obsesionado por mucho tiempo a grandes pensadores; una concepción que fue revivida por cierto en los años sesenta con el grupo Tel Quel, la desconstrucción, y sus diferentes legados. Quisiera, por ende, desviarme un momento de estas obras para explicar mejor lo que trato de hacer en esta exploración.

Parto desde luego con la filosofía clásica. Aristóteles en un fragmento de su trabajo sobre La política, ampliamente citado por muchos pensadores, hace una distinción muy importante entre el ruido y la voz (entre lo que él denomina en griego como "phoné" y "logos"). Esta diferenciación va a servir de soporte para muchas de las concepciones hegemónicas de lo humano. Para el filósofo, mientras que el "logos" -la "palabra" articulada- es propio del hombre; el "ruido" sólo es de los animales; una permite el juicio de lo que es conveniente y de lo que no lo es; la otra, sólo permite expresar sentimientos y sensaciones. ${ }^{15}$

La primera es entonces propia del hombre, como ser racional, mientras que la segunda es propia de todo animal; una no es sólo sonido puro, sino que está sublimada

15 Cito la traducción en inglés, que establece la diferencia entre las palabras "speech" y "voice": "For nature, as we declare, does nothing without porpuse; and man alone of the animals posseses speech. The mere voice, it is true, can indicate pain and pleasure (...), but speech is designed to indicate the advantageous and the harmful, and therefore the also the right and the wrong" (Politics, 1.1253a)

$111 \frac{\text { Revista Iberoamericana, Vol. LXXXII, Núms. 255-256, Abril-Septiembre 2016, } 551-569}{\text { ISSN 0034-9631 (Impreso) }}$ 
y articulada por la razón, por el "logos", y la otra, que también tienen los seres humanos por ser seres vivientes -donde expresa sus sentimientos y emociones-, es sonido inarticulado, sin sentido. Una corresponde a una lógica digital: la información se divide en canales binarios, dados en este caso por el alfabeto; la otra, a una lógica analógica: el flujo informativo pasa sin ser diseccionado; cosa que, siguiendo la nomenclatura de Lacan, podría ser entendido como una figura de lo "simbólico", y la otra, como una figura de lo "real". ${ }^{16}$

En ese extracto se resume uno de los gestos metafísicos por excelencia de Occidente que ha querido emparentar voz con razón, excluyendo toda sonoridad que no sea pulida y disciplinada por el orden articulado. También en su Poética nos habla de la voz como "phone semantike", es decir, como "voz con sentido". Es el principio de la gramática y la ortografía, de la escritura entendida como inscripción reglamentada y lógica, con enunciados claros y precisos. Esta "voz" se hace más visible, más personal, más íntima, cuando con el Renacimiento se introduce la práctica de la lectura silenciosa, albergando así el espacio para el desarrollo de la idea de sujeto moderno, completamente autónomo y racional. A partir de ese momento se naturaliza y expande en las culturas del libro, gracias a la imprenta, la noción de voz articulada como el elemento propiamente humano, negando y excluyendo otras sonoridades y ruidos, que sólo reaparecerán como marcas de violencia bárbara, o como espacios de alteración disruptiva cercanos a la locura, el sentimiento desmedido, o la niñez.

Recientemente los acercamientos de Jean-Luc Nancy, Adriana Cavarero, Mladen Dolar o Giorgio Agamben han repensado el lugar de la voz en nuestra cultura y han querido mostrarnos cómo gran parte de la filosofía occidental ha querido excluirla, o verla si no con desdén al menos con cierta despreocupación. ${ }^{17}$ En América Latina las

${ }_{16}$ Sigo en este sentido a Friedrich Kittler, quien en sus trabajos Gramaphone, Film, Typewriter (1999) y Discourse Network 1800/1900 (1985) ha usado ambas analogías para explorar los diferentes sistemas de inscripción. Si bien uso un vocabulario prestado de la cibernética, para distinguir las lógicas de ambas sonoridades, creo que es válida verlas desde esa distinción, que el mismo Kittler usa. Me permito citarlo en detalle en uno de sus trabajos cuando trata de explicar la diferencia entre el sistema analógico y el digital: "in the first case, the signal generated by the sender corresponds proportionally to the message, which means that it follows all of its changes in space and/or time. This is called analog communication, as in the case of gramaphone, microphone, radio or even photography [...]. In the second case, the message is broken down into its pure constitutent elements prior to transmission in order for it to fit the capacity of the channel" (45)

${ }_{17}$ Mientras Agamben en Language and Death (1991) destaca el valor negativo de la Voz, como lugar de actualización del lenguaje donde el sentido todavía no ha tenido lugar, Cavarero en For More Than One Voice: Toward a Philosophy of Vocal Expresión (2005) se concentra por el contrario en la "fisicalidad" misma del sonido como marca y evidencia de una otredad, más allá de la experiencia del significado. Nancy en A la Escucha (2007) trabaja, por su lado, el tema de la resonancia (de la capacidad que tiene la voz de resonar en nosotros) -y la diferencia del ruido por ese elemento que se da antes del evento propio de lo que se enuncia o dice-. En contraposición, a Dolar en A Voice and Nothing More (2006) le

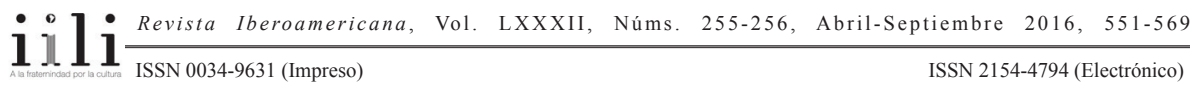


recientes exploraciones de Julio Ramos, siguiendo algunas de estas ideas, abren un nuevo camino para entender el inmenso mundo sonoro que se dio en el Caribe y que fue claramente excluido por la racionalidad moderna. ${ }^{18}$

En suma, y volviendo un poco a las poéticas de Cabrera Infante y a las de Barnet, mientras ciertos discursos ideológicos que amparan al género testimonial, provenientes de cierto marxismo y de cierta antropología, pretenden todavía sustentar sus presupuestos en una visión del sentido como algo transparente y asequible a la racionalidad; todavía cierta zona de la literatura, considerando algunas de sus limitaciones materiales y culturales -como su vínculo con la máquina académica, sus claras marcas con viejos resabios de clase, su secreta nostalgia por el orden letrado de las Bellas Letras, o como su dependencia con las tecnologías de la escritura y con las lógicas del mercado-, intenta establecer otras formas de diálogo con la otredad que no estén supeditadas al contrato hermenéutico, ni a sus formas de exclusión logocéntricas.

No se trata de privilegiar una práctica sobre la otra, pues desde cierta perspectiva, y como bien nos lo señala Roberto González Echevarría en “"Biografía de un cimarrón' and the Novel of the Cuban Revolution" (1983) con la obra de Barnet, el testimonio también es "literatura", sobre todo al momento de convertirse en inscripción escrita y lidiar con problemas de estilo y corrección. Además, son numerosos los casos de trabajos testimoniales, donde esta representación articulada, lógica y ortográfica de la voz queda suspendida, o puesta en cuestión: me viene a la mente en este caso la obra de Diamela Eltit El padre mío, por ejemplo.

Para explicar mejor este sentido de la "voz"-si es que tiene algún "sentido", fuera de un contenido o esencia-, quisiera detenerme brevemente en un texto que considero importante para indagar sobre esta temática. Me refiero a un trabajo de María Fernanda Palacios, escrito en los años ochenta, donde nos habla de esta otra experiencia de la voz que puede hacerse visible en formas de escritura literaria. En Sabor y saber de la lengua (1984) nos habla del "cuerpo de la lengua" y en un momento trata de definírnoslo como una voz "porque es lo más efímero, lo más seductor, lo más ficticio lo menos significativo de un mensaje" (17). Más adelante nos explica, con un tono reminiscente de los trabajos de Nancy, algunas ideas importantes sobre el acto de lectura:

interesa, siguiendo a Lacan, la voz como un evento no discursivo -casi como lo "real", que si bien no tiene orden lógico, o de sentido, tiene un valor importante como mandato- aunque se concentra también en su relación con el "objeto A", y sobre todo en las maneras como desde la política, la ética y el derecho ha sido representada.

18 Varios trabajos "caribeñistas" han ido reflexionando sobre este tema recientemente, desde el libro sobre la salsa de Juan Carlos Heredia. La máquina de la salsa. Tránsitos del sabor, pasando por Ángel Quintero y Rivera con su Salsa, sabor y control. Sociología de la música tropical (1998) y el trabajo de Juan Otero Gabarís, Nación y ritmo. "Descargas" desde El Caribe. Recientemente Julio Ramos con su texto "Descarga acústica", aparecido por cierto en un antología de investigaciones que él mismo recopila sobre el tema de la música en el Caribe, nos da un buen ejemplo de esta interesante línea de trabajo.

$111 \frac{\text { Revista Iberoamericana, Vol. LXXXII, Núms. 255-256, Abril-Septiembre 2016, } 551-569}{\text { ISSN 0034-9631 (Impreso) }}$ 
Esa voz del autor que llega hasta nosotros nunca es una abstracción; tampoco se trata del componente acústico; no es sonido sino repercusión imaginativa. Por lo tanto, la voz (esta voz) no puede ser formalizada o conceptualizada. En esta voz no percibo la puntuación gramatical sino la otra, la irregular, de su escucha (su pulso); la puntuación que no viene dictada por las reglas sino por la emoción. El verdadero tempo de una frase. Puntuación no de signos de puntuación sino de pausas inesperadas, balbuceos, énfasis, disminuciones. Y la relación que mantenemos con un autor depende, en última instancia, de esa voz. Es una relación sujeta a la escucha (atenta, memoriosa, imaginativa) de los efectos de esa voz en nosotros. (42)

Pese a que María Fernanda Palacios excluye un componente esencial de la materialidad de la voz, su sonoridad, me interesa detenerme en su idea de la "repercusión imaginativa" que ya no vemos como algo gramatical, sino como un lugar que escapa al sentido. Sólo desde este escape es que podemos darle espacio al "otro" en nosotros. "Porque el verdadero diálogo no consiste tanto en entender lo que el otro dice sino en atenderlo (hacerle sitio)" (18), dice la autora. Sin duda, todo hecho testimonial reside en este momento, importantísimo, de dar cabida a toda figura de alteridad, de "hacerle sitio". Un momento que, sin embargo, puede perfectamente borrarse en el ejercicio de la escritura y su contexto enunciativo, pero también en la poética que domine la representación de la voz, ya no como acto de resonancia, sino como enunciado ortográfico, donde la voluntad de poder del significado termina por adueñarse de la escena de encuentro. Ahí reside el poder y la limitación de todo "hecho testimonial", que abre y cierra la voz.

Cuando la voz cede al sentido y a la articulación entramos, por ende, en otro dominio, en el dominio del derecho y la legalidad, cuyo fundamento es indisociable con la escritura fonética. Para Aristóteles efectivamente la palabra articulada le da cualidades al hombre para emitir juicios de lo bueno y de lo malo. Testimoniar se convierte así en una forma de juzgar, de reivindicar derechos ciertamente, pero también intereses y figuras de poder. No en balde la novela testimonial de Barnet se da en paralelo con los dispositivos de escenificación de la "voz" revolucionaria como figura de lo nacional (sobre todo del "pueblo"), y que tiene como epítome el discurso "Palabras de los intelectuales" de Fidel. Este vínculo no sirve sino para juzgar y determinar lo cubano, frente a lo foráneo, lo peligroso, como bien nos describe Quintero Herencia: “"Dentro de la Revolución: todo; fuera de la Revolución nada' constituiría un gesto hueco, una perogrullada, en tanto el Líder ha proclamado un estatuto legal que define, funda y recorta el 'interior' nacional" (364). Y esta delimitación se da en la puesta en escena del mandato: "La Voz que arma esta Ley emana desde los adentros de la Patria; la Voz es el adentro nacional, sus afueras no son, no existen como posibilidad para el ser revolucionario" (365).

El testimonio viene del latín "testimonium", que significa "valores de la forma". El Diccionario de la Real Academia lo define como "aseveración de una cosa", y como "instrumento autorizado por escribano o notario, en que se da fe de un hecho" (1305).

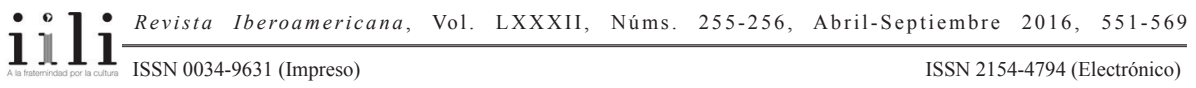


Es entonces un documento imparcial, que sirve para "testimoniar" un acontecimiento, para dar prueba de algo que se juzga o se revisa. Este principio de legalidad sobre el cual se ha fundamentado parte de su uso, al menos en el castellano, podría asociarse a las formas del "derecho positivo" según nos advierte Walter Benjamín en "Para la crítica de la violencia", en donde el dato del documento como hecho empírico se aísla de su realidad global y se inscribe en un círculo de "violencia mítico". ${ }^{19}$

Sin embargo, el testimonio de Montejo tiene como trasfondo el enjuiciar la historia misma de Cuba antes de la revolución, sin jurado ni abogados defensores, por cierto. Sería así una especie de juicio sumarial y mesiánico, donde la "voz" como "logos" es el principio de toda verdad, al margen de las especificidades sociales y culturales del lugar de enunciación; una forma, para volver a Benjamín, más bien de instrumentalización del "derecho divino".

Volvamos a Cuba. Por lo visto hasta ahora, podemos decir que dentro del espacio simbólico de la cubanidad, la oralidad revolucionaria del pueblo, que bien representa la obra de Barnet y los numerosos testimonios que se dieron en esas épocas, y el modelo de Cabrera Infante, ocupan coordenadas disímiles y extremas que sólo se tocan para repelerse y excluirse. Mientras que el primero se inscribe en la tradición logocéntrica, que privilegia la voz articulada por encima de cualquier otro elemento; Cabrera Infante muestra por el contrario, y acaso pese a sí mismo, otras sonoridades, que lindan con la música, con el ruido producido por otras tecnologías, con los acentos de otros sujetos no letrados.

Si uno oculta sus mecanismos y mediaciones, el otro las pone en evidencia. Uno pule y limpia, el otro desgarra y deja aflorar; uno busca una zona de inteligibilidad total, desde la seriedad del compromiso ideológico, el otro muestra su opacamiento, desde el nihilismo del humor resentido y agónico; uno deifica, el otro niega; uno privilegia un sujeto pre-moderno, inocente, esencial, puro; el otro lo abre a la contaminación, a los conflictos e ilusiones de clase, a las fantasías de la modernización y los males del capitalismo moderno. Ambos, sin embargo, comparten una misma búsqueda: la que conjura ese espectro de la cubanidad, que la revolución ontologiza, mientras que Cabrera Infante lo pone en cuestión y lo abre a la pluralidad.

\footnotetext{
19 Walter Benjamin dice sobre el derecho positivo y la violencia mítica: "La función de la violencia en la creación jurídica es, en efecto, doble en el sentido de que la creación jurídica, si bien persigue lo que es instaurado como derecho, como fin, con la violencia como medio, -sin embargo, en el acto de fundar como derecho el fin perseguido- no depende en modo alguno la violencia, sino sólo ahora hace de ella en sentido estricto, es decir, inmediatamente, violencia creadora de derecho, en cuanto instaura como derecho, con el nombre de poder, no ya un fin inmune e independiente de la violencia, sino íntima y necesariamente ligado a ésta" (39-40).
}

$111 \frac{\text { Revista Iberoamericana, Vol. LXXXII, Núms. 255-256, Abril-Septiembre 2016, } 551-569}{\text { ISSN 0034-9631 (Impreso) }}$ 
ParaAntonio Vera-León en "Juan Francisco Manzano: el estilo bárbaro de la nación” gran parte de los textos fundacionales de la literatura cubana supusieron "una relación estrecha entre la escritura y la oralidad" (12). Una relación, que no fue armoniosa, sino que por el contrario mostraba una escisión insalvable, un hueco imposible de llenar. El gesto fundacional del Grupo de Del Monte de corregir la confesión del esclavo bien lo ejemplifica. "De manera que la prosa fundacional cubana -como bien destaca VeraLeon- surge como una zona que no logra resolver el choque entre el lenguaje bárbaro, oral, y el proyecto de su domesticación en la escritura" (19).

Miguel Barnet, y el género testimonial que se produjo en Cuba en la era revolucionaria, resuelve este dilema anulando cualquier resquicio de duda o escape; la letra es lo oral -la pulcra e inocente "oralidad"-, lugar de esa parte de Cuba que ha sido marginada y que representa al "pueblo": sujeto colectivo, armónico y orgánico, que está presente de manera impoluta al menos en la década de los sesenta y setenta en Montejo. Entre tanto, Cabrera Infante exacerba el gesto de esta imposibilidad; la letra no puede representar ese momento, queda frustrada en sus registros. Uno reinstaura el pacto entre letra y voz, inscribiéndose en eso que una vez Derrida llamó la violencia "logos-céntrica", y el otro lo disemina, mostrando más bien sus huecos, fracturas, traumas. Consecuencia: Cabrera Infante quedó afuera, y Barnet adentro. "Por ello le echó del jardín del Edén, para que trabajara la tierra de donde había sido formado" (Génesis 3:23), se explica en la Biblia sobre lo que había decidido la voz celestial, que en este momento no habló, sino actuó.

\section{BiBLIOGRAFÍA}

Agamben, Giorgio. Language and Death: The Place of Negativity. Karen E. Pinkus y

Michael Hardt, trads. Minneapolis: Regents of the University of Minnesota, 1991. Aristotle. Politics. Cambridge: Harvard UP, 1944.

Barnet, Miguel. Biografía de un cimarrón. Barcelona: Ediciones Ariel, 1968.

Canción de Rachel. Habana: Letras Cubanas, 1993.

"Testimonio y comunicación: una vía hacia la identidad". La fuente viva. La Habana: Letras vivas, 1983.

"La novela testimonio: socio-literatura". La fuente viva. La Habana: Letras vivas, 1983.

Benjamin, Walter. "Para la crítica de la violencia". Ensayos escogidos. H.A. Murena, trad. México: Ediciones Coyoacán, 1999. 109-129.

Biblia. Quito: Editorial Verbo Divino, 1989.

Cabrera Infante, Guillermo. Así en la paz como en la guerra. La Habana: Ediciones Revolución, 1964.

Tres tristes tigres. Barcelona: Seix Barral, 1967.

Tres tristes tigres. Barcelona: Seix Barral, 2005.

Vista del amanecer en el trópico. Barcelona: Seix Barral, 1974.

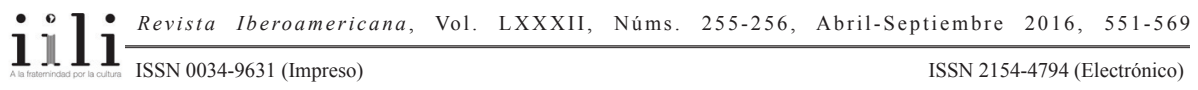


Exorcismos de Esti(l)o. Barcelona: Seix Barral, 1976.

Un oficio del siglo XX. Barcelona: Seix Barral, 1973.

Cavarero, Adriana. For More Than One Voice: Toward a Philosophy of Vocal Expresion.

Paul A. Kottman, trad. Stanford: Stanford UP, 2005.

Castro, Fidel. "Las Palabras sobre los intelectuales". La Revolución Cubana. México:

Ediciones Era, 1972. 356-379.

Derrida, Jacques. "La farmacia de Platón. La diseminación. Madrid: Fundamentos, 1975.

Díaz Infante, Duanel. "Bibliotecas, decretos y paradojas". El Veraz. Com Semanario.

23 sept. 2008. <http://www.elveraz.com/articulo762.htm>. 13 julio 2015.

Dólar, Mlcaln. A Voice and Nothing More. Massachusets: MIT UP, 2006.

González Echevarría, Roberto. "'Biografía de un cimarrón': And the Novel of the Cuban Revolution". Novel: A Forum on Fiction 13/3 (1980): 249-263.

“"Meta-Final', de Guillermo Cabrera Infante, con comentario, notas y traducción al inglés". La voz de los maestros: escritura y autoridad en la literatura latinoamericana moderna. Madrid: Verbum, 2001. 223-231.

Guerrero, Gustavo. Historia de un encargo: “La catira” de Camilo José Cela. Barcelona: Anagrama, 2002.

Heredia, Juan Carlos. La máquina de la salsa. Tránsitos del sabor. San Juan: Vértigo, 2005.

Hutton, Christopher. "Language as Identity in Language Policy Discourse: Reflections ona a Political Ideology”. Lengua, Nación e Identidad: la regulación del plurilingüismo en España y América Latina. Kirsten Süselbeck y Ulrike Mühlschlegel, eds. Madrid: Iberoamericana, 2008. 75-82.

Kittler, Friedrich. Gramophne, Film, Typewriter. Geofrey Winthrop-Young y Michael Wutz, trads. Stanford: Stanford UP, 1999.

Optical Media. Cambridge: Polito Press, 2010.

Ludmer, Josefina. "Tres tristes Tigres: órdenes literarios, jerarquías sociales". Revista Iberoamericana XLX/108-109 (1979): 493-512.

Nancy, Jean-Luc. A la escucha. Horacio Pons, trad. Buenos Aires: Amorrortu, 2007.

Ortiz, Fernando. Contrapunteo del tabaco y del azúcar. Madrid: Cátedra, 2002.

Otero Gabarís. Nación y ritmo. "Descargas” desde el Caribe. San Juan: Callejón, 2000.

Palacios, Maria Fernada. Sabor y saber de la lengua. Caracas: Otero Ediciones, 2004.

Quintero Herencia, Juan Carlos. Fulguraciones del espacio: Letras e imaginario institucional de la Revolución Cubana (1960-1971). Rosario: Beatriz Viterbo Editora, 2002.

Quintero y Rivera, Ángel. Salsa, sabor y control. Sociología de la música tropical. México: Siglo XXI, 2005.

Ramos, Julio. "Descarga acústica". Papel máquina II/4 (2010): 49-77.

Ríos, Valeria de los. "El cine, el gramófono y la máquina de escribir: TTT, novela mediática latinoamericana”. Espéculo. Revista de Estudios literarios 28. Universidad

$111 \frac{\text { Revista Iberoamericana, Vol. LXXXII, Núms. 255-256, Abril-Septiembre 2016, } 551-569}{\text { ISSN 0034-9631 (Impreso) }}$ 
Complutense, 27 nov. 2004.<http://www.ucm.es/info/especulo/numero28/ttt_cabr. html>. 13 julio 2015.

Santí, Enrico Mario. Introducción. Contrapunteo del tabaco y del azúcar. Madrid: Cátedra, 2002. 25-103.

"Testimonio". 2. Diccionario de la Real Academia de la lengua. Madrid: Real Academia Española, 1985.

William, Luis. “'Aire puro me gusta el aire puro': P.M., Lunes de Revolución, y la composición de Tres tristes tigres, de Guillermo Cabrera Infante". Cuba: un siglo de literatura (1902-2002). Roberto González Echevarría y Anke Birkenmair, eds. Madrid: Editorial Colibrí, 2004. 221-244.

Vera-León, Antonio. "Juan Francisco Manzano: el estilo bárbaro de la nación". Hispamérica XX/60 (1991): 3-22. 
